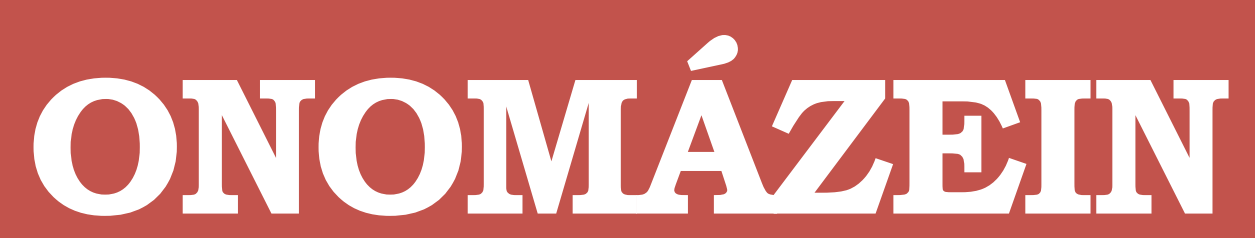

Journal of linguistics, philology and translation
PONTIFICIA UNIVERSIDAD

\title{
Did you draw what I wanted to say? \\ Picture-Text Dynamics and Intersemiotic Translation in Roald Dahl's Matilda
}

\author{
Bruno Echauri Galván \\ Universidad de Alcalá \\ españa
}

\section{(C) $($ ii) $\ominus$}

Bruno Echauri Galván: Facultad de Filosofía y Letras, Edificio Caracciolos, Universidad de Alcalá, España | E-mail: bruno.echauri@uah.es 


\section{Abstract}

The present paper is an analysis of the illustrations of Roald Dahl's Matilda (2016 [1988]) through the prism of intersemiotic translation. The main purposes of this study are to determine the type of relationships established between text and pictures in the novel and to identify how the illustrator represents some of its main topics, to wit: the importance of books and education, adults' abuse of power, rebellion, and school mistreatment. In order to achieve these objectives, the paper analyzes the interrelation between several passages of the text and their corresponding illustrations. Subsequently, the study categorizes the different dynamics established between text and pictures and discusses how some procedures connected to Translation Studies can be aligned with the decisions taken by the illustrator when depicting the foregoing themes. As a result, the paper concludes that Matilda's illustrations work as emphasizers of some of the messages Dahl intended to transmit to his readership when writing this book.

Keywords: Roald Dahl; translation procedures; intersemiotic translation; children literature; picture-text dynamics. 


\section{Introduction}

Albeit he has written several novels and adult stories, Roald Dahl is popularly known as the author of some of the most notable children books of the second half of the $20^{\text {th }}$ century. From James and the Giant Peach to The Witches through Charlie and the Chocolate Factory, Dahl's children literature has been a global success. However, most of these stories are built against the background of a selfish society and conceal solid and perennial corollaries that transcend childhood and early adolescence. These sorts of two-faced novels, enjoyable by both kids and adults, hide more than we can appreciate after a first reading. What may seem a simple story - full of humor, hyperboles, and pranks - becomes a deep social critique and a vindication of literature when closely analyzed.

For most of these stories, Dahl has relied on Quentin Blake as his main illustrator. Both artists collaborated in several tales and novels such as The Twits, The BFG, or Matilda (Kenyon, 2016), the novel this paper revolves around. In this vein, Blake's illustrations have always played an important role in providing a visual explanation and reinforcing the humor contained underlying the most relevant events in the plot. But beyond this obvious fact, a thorough analysis can uncover further dynamics and conclusions that stem from the symbiosis established between text and drawings in cases as Roald Dahl's Matilda (2016 [1988]). The following paper seeks to drill down into this interrelation in order to highlight other functions of Blake's illustrations that a superficial analysis may overlook.

\section{State of the art}

A popular writer as he is, Roald Dahl's novels and short stories have been widely addressed by researchers and scholars. Literary analyses have been conducted on most part of his work, addressing issues such as racialization, patriarchy, parenthood or humor (Curtis, 2015; De Juan, 2016; Keyser, 2017; Martín Ortiz, 2009). As for the particular case of Matilda, the novel has been studied from different perspectives by authors such as Del Fresno (2009), Guest (2008) or Petzold (1992), each one of them addressing some of the main features and topics concealed in the pages of this apparently innocent novel, to wit, rebellion, social satire, or adulthood among others.

As for its conversion into other languages, the translations of Matilda have also been a matter of study. Works like Alsina's (2012) or Netley's (1992) have explored the complexities of translating some of the most particular aspects of this novel such as cultural signs or linguistic variation into different languages such as Japanese, Spanish, or Catalan. However, Matilda lacks studies addressing the interrelation established between the text and its illustrations. This paper seeks to intertwine literary analyses of the novel with the field of intersemiotic translation in order to provide a groundbreaking approach to the work of one of the most famous British storytellers of the second half of the $20^{\text {th }}$ century. 
In this vein, the present paper intends to reach two main objectives:

— To identify how some of Matilda's main topics are represented in the illustrations of the work.

- To determine the type of relationship between the text and illustrations of the book.

In addition to reaching these objectives, the paper also seeks to explore the following hypothesis: Matilda's illustrations are intersemiotic translations aimed partly at emphasizing some of the core topics of the novel.

\section{Theoretical framework}

As stated in the previous section, this paper intends to analyze the connection between core issues addressed in Dahl's novel and the way Quentin Blake decided to illustrate the words of the Welsh writer. In order to do this, the study firstly identifies a list of notable topics discussed in Dahl's novel. In this regard, I have decided to focus on the following four themes: books and education, adults' authoritarianism, rebellion, and school mistreatment. Each one of these topics will be discussed independently in the analysis section of the paper. Firstly, the presence and relevance of every theme will be explained with the support of literary research on the novel; subsequently, an analysis of the illustrations addressing each specific topic will be conducted.

The channel linking these two different codes (text and illustrations) is intersemiotic translation (also known as "transmutation"). This concept, coined by Jakobson (2000 [1959]), spans those translations that occur between different sign systems or media. In other words, transmutation creates a field in which the same message is transmitted via different semiotic forms with different levels of correlation between the source and the final result (Torop, 2003). Accordingly, this type of translations could range from an autonomous to a complementary target version (Torop, 2003). This latter category could apply to the focus of this study, since the level of convergence between a text and its corresponding illustration tends to be high (Lotman, 2001). However, the dynamics that stem from this interaction may vary and pave the way for a more complex categorization.

One of the first attempts to classify the nexus between a text and its illustrations was proposed by Schwarcz (1982), who divided this relationship into deviation and congruency. But subsequent research has provided a more thorough classification of the dynamics created by the relationship between texts and pictures. One of the most notable efforts in this regard was undertaken by Nikolajeva and Scott (2000). The taxonomy created by these authors establishes five possibilities: symmetrical, enhancing, complementary, counterpointing, or contradictory interaction. The first category describes situations in which words and pictures state basically the same information. The second one refers to a dynamic in which the text 
expands on the meaning of illustrations or vice versa; when this dynamic proves to be really significant, it becomes a case of complementary interaction. The fourth case, a counterpointing dynamic, occurs when pictures and words provide alternative information. Extreme cases of this dynamic could be labeled as contradictory interactions.

It is worth stressing that the same authors stated that these are not absolute categories: boundaries are fuzzy and it is difficult to classify an illustration or series of illustrations under a sole category. Along these lines, as it will be later discussed, Blake's pictures in Roald Dahl's Matilda (2016 [1988]) would mostly range among the concepts of symmetrical, enhancing, and complementary interaction. However, in the last two cases, illustrations do not only complement or expand on Dahl's text. By doing this, they also underline some of the most relevant features of the novel. Thus, by analyzing some of the engravings in Matilda through the prism of transmutation I intend, as my hypothesis states, to prove that several illustrations in this book work as emphasizers of several core topics addressed by Dahl throughout the novel.

In this respect, some decisions taken by Blake to highlight the relevance of certain themes that are essential for understanding this work could be compared to different techniques connected to Translation Studies. In other words, Blake depicts situations in a way that could be aligned with a number of translation procedures, resulting in the aforementioned emphasis. In this vein, the procedures this paper identifies and discusses are Vinay and Darbelnet's (1995) literal translation ${ }^{1}$ (a final product which reflects the content of the source text as accurately as possible), Hurtado Albir's (2001) amplification (adding information which was not present in the ST), and Ray and Kelly's (2010) transcreation (a case of very-free translation by which the illustrator develops new content instead of translating the original directly in order to make his work more palatable for the target audience). In addition, certain choices related to the illustration patterns followed throughout the book or the situations Blake chooses to make visible also have a special impact on underlining the main topics of the novel.

\section{Methodology}

The present paper combines a hypothetico-deductive method with a comparative analysis between text and illustrations. The former implies building a hypothesis that will be subsequently tested by observation (or analysis in this case) in order to check whether the initial claim is true or false. And this is precisely the structure on which this study is built.

1 Regarding this procedure, it is worth stressing that there are obvious limitations and constraints that stem from the change from one code into a different one. Therefore, the concept "literal" should be understood as an attempt of the illustrator to remain as faithful as possible to the passage he is depicting, regardless of the compulsory modifications imposed by the target media. 
In the case of the latter, the analysis is based on the comparison between several passages and their corresponding drawings in the primary source-Roald Dahl's Matilda (2016 [1988]) - . The purpose of this examination is to ferret out some of the strategies Quentin Blake uses to emphasize the main topics in Dahl's novel via illustrations. In this vein, certain structural patterns used by the illustrator are studied. In addition, I try to establish a parallelism between some of Blake's decisions and Translation Studies by creating an analogy between them and the translation procedures introduced before: transcreation, amplification, and literal translation.

The use of the abovementioned techniques creates different dynamics between narrative and non-narrative elements. Thus, the next stage of the analysis consists in determining what kind of relationship is established between Dahl's passages and Blake's pictures. These dynamics are studied in different sections of the novel where topics like adult's abuse of power, school mistreatment, rebellion, and the importance of literature and education are clearly addressed. It is expected that the sum of the illustrator's decisions and the dynamics they create in these passages of the novel will eventually clarify whether the initial hypothesis can be corroborated or disregarded.

\section{Analysis}

The importance of literature and education is one of the most relevant messages Dahl intends to transmit in Matilda. Dahl's daughter, Lucy, acknowledged this in an interview with Robert Siegel and Audie Cornish (2013), where she stated that the Welsh author wrote this book out of his fear "that books were going to go away" (para. 6). In addition, Dahl's novel addresses several issues associated with the field of education, such as the suitability of different methodologies, the importance of reading promotion plans, or the impact of professors and families in children's education among others (Quiles Cerrillo, 2016). The relevance of these two issues and the binary positions portrayed throughout the book become firstly evident when we confront the light under which Matilda is intellectually described with the depiction of other characters like her parents. While the former is "...brilliant. Her mind was so nimble and she was so quick to learn that her ability should have been obvious even to the most half-witted of parents" (p. 4), the latter are "so gormless and so wrapped up in their own silly little lives that they failed to notice anything unusual about their own daughter" (p. 4). Matilda's physical appearance is also an interesting case of study, but it will be discussed later in the paper.

Nevertheless, the importance of literature and education is not only emphasized through words, but also via the illustrations in the book. The first visual contact we establish with Matilda occurs on page 1 , and it depicts a smiling girl with an open book on her hands. Underneath this picture we can read the title of the first chapter "The Reader of Books" (see figure 1). However, the first written description of the girl appears on page 4, and it does not focus 
on her love for books, but on how "extra-ordinary" she is and on the brilliant mind she has. In my view, Blake's relocation of Matilda's first depiction together with the addition of an extra element like the book serves two main purposes: it foregrounds the main character of the novel and also a core topic within Dahl's story-the importance of literature.

\section{FIGURE 1}

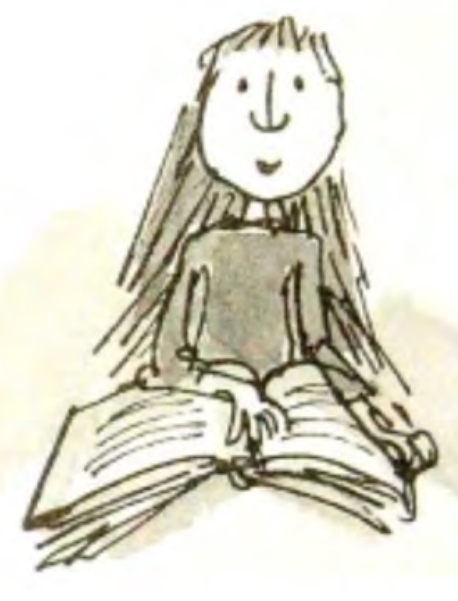

Throughout the first pages of the novel, Matilda always appears surrounded by books or other reading materials. That is the case of pages $5,6,8,11$ and 13 (by means of example, see figure 2), where the girl "studies newspapers and magazines", reads "from cover to cover" her mother's cookbook, or sits on the library's couch "totally absorbed" in "wonderful adventures". All these and other passages related to reading could be labeled as examples of literal translation between different systems, since Dahl's words are directly reflected in Blake's engravings. In this instance, Blake creates a symmetric dynamic between text and illustrations. This decision implies including reading materials in almost all the appearances of the little girl, which helps settle the connection between the protagonist and books, and underlines literature and education as a core topic using both narrative and non-narrative elements.

\section{FIGURE 2}
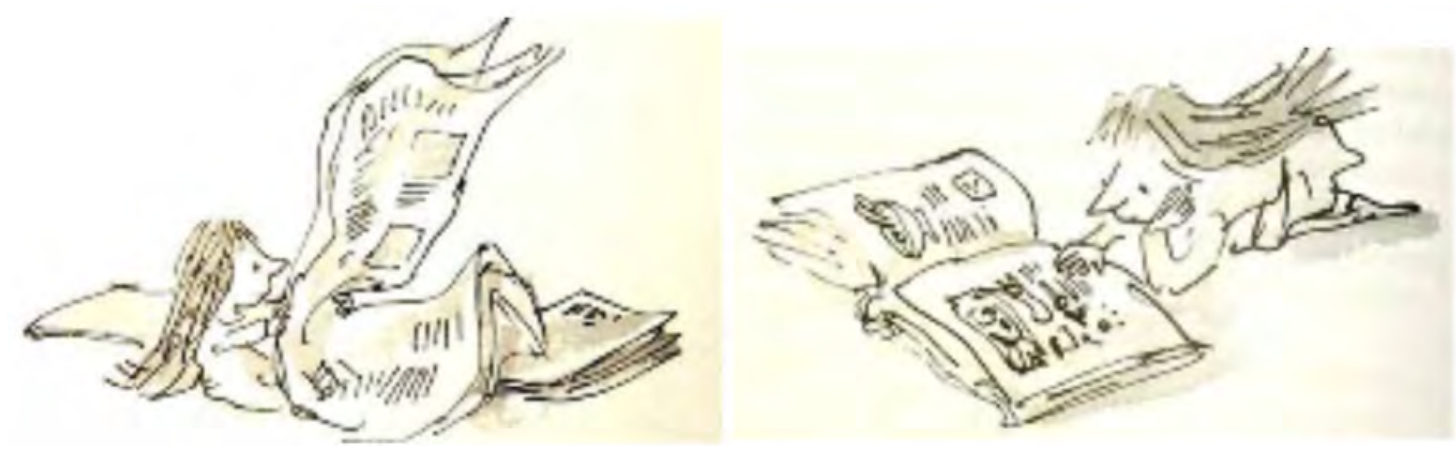
In subsequent chapters, however, the linkage between Matilda and literature is reinforced by adding the presence of books to the picture even when they are not explicitly mentioned in the text. This is the case, for instance, of the chapter "Arithmetic", where Matilda solves the calculations her father is dictating her brother. In this case, Matilda is depicted two times with a book on her hands (pp. 47 and 49). Nevertheless, Dahl never mentions this fact throughout the chapter: the assumption signified by Blake here strengthens the indissoluble duo formed by Matilda and literature. As opposed to the cases described in the previous paragraph, where a literal translation created a symmetrical dynamic between text and pictures, Blake's additions here build examples of enhancing dynamics.

Adults' baseless abuse of power is another recurrent topic in Dahl's literature. Few testimonies could be more enlightening to this effect than the own author's: "The adult is the enemy of the child because of the awful process of civilizing this thing that when it is born is an animal with no manners - no moral sense at all" (Pope and Round, 2015: 2). This vision is probably based on the author's own experiences. In Boy (1984), the first part of his memoirs, Dahl recalls his experience at the public school of Repton, and the cruel behavior of its headmaster, who believed in education through corporal punishment as a means of education. This aversion against the tyranny imposed by some adults has permeated most of Dahl's children bibliography. And Matilda is just another case in point.

In this vein, the portrayal of some characters reinforces this image of adults as villains or disgusting figures. The most obvious case is that of Miss Trunchbull, the school's principal. Her depiction is another example of literal translation where all the textual elements mentioned by Dahl are subsequently translated into visual elements. Thus, Miss Trunchbull is drawn as an enormous woman, with a "bull-neck", "big shoulders", "thick arms, "sinewy wrists" and "powerful legs" (pp. 76-77), always wearing "a brown cotton smog, a belt with a silver bucket, bottle-green breeches made of coarse twill and green stockings with turn-up tops" (p. 77). In this instance, the text and its corresponding engraving are a perfect fit.

The case of Matilda's parents is also paradigmatic when it comes to represent tyranny, malice, and stupidity. Throughout the novel, recurrent allusions to their personality tend to be extremely pejorative. For instance, one of the passages in the book states that "Matilda longed for her parents to be good and loving and understanding and honorable and intelligent. The fact that they were none of these things was something she had to put up with." (p. 43). But there are other examples in which Blake has added certain elements to the illustration that eventually have helped emphasize the negative portrait of adult bullies.

The physical appearance of Mr. and Miss Wormwood is shown under the same negative light as their character (see figure 3). While he is described as "a small ratty-looking man whose front teeth stuck out underneath a thin ratty moustache" (p. 17), his wife is presented as "a large woman" who "wore heavy make-up and she had one of this unfortunate bulging figures 
where the flesh appears to be strapped in" (pp. 20-21), or as "the plain plump person with the smug suet-pudding face" (p. 92). All these narrative elements are translated into pictures by Blake. But in both cases, the amplification process followed by the illustrator reinforces the image conveyed by Dahl. In the case of the father, the nose is a significant feature to analyze: long and sharp, it gives Mr. Wormwood a more threatening face. Likewise, the most salient inclusions in Mrs. Wormwood's depiction are the jewelry and accessories she is constantly wearing. In my view, the emphasis here lies not on the ornaments themselves, but on the situations she models them: Mrs. Wormwood is never depicted outdoors, and she even cooks with her jewelry on. By portraying her in this manner, Blake underlines two of her most notable features: plainness and stupidity.

All things considered, the case of Matilda's parents is a perfect example of enhancing dynamic. In this instance, Blake's additions help emphasize the relationship between adults and evil Dahl intended to create. The abovementioned pictures include information the text does not contain, providing the reader a more detailed picture than Dahl's regarding the physical descriptions of Matilda's parents. Likewise, this depiction reinforces the topic of adults' baseless abuse of power, since it highlights the malice of one of the characters and the ridiculous portrayal of the other.

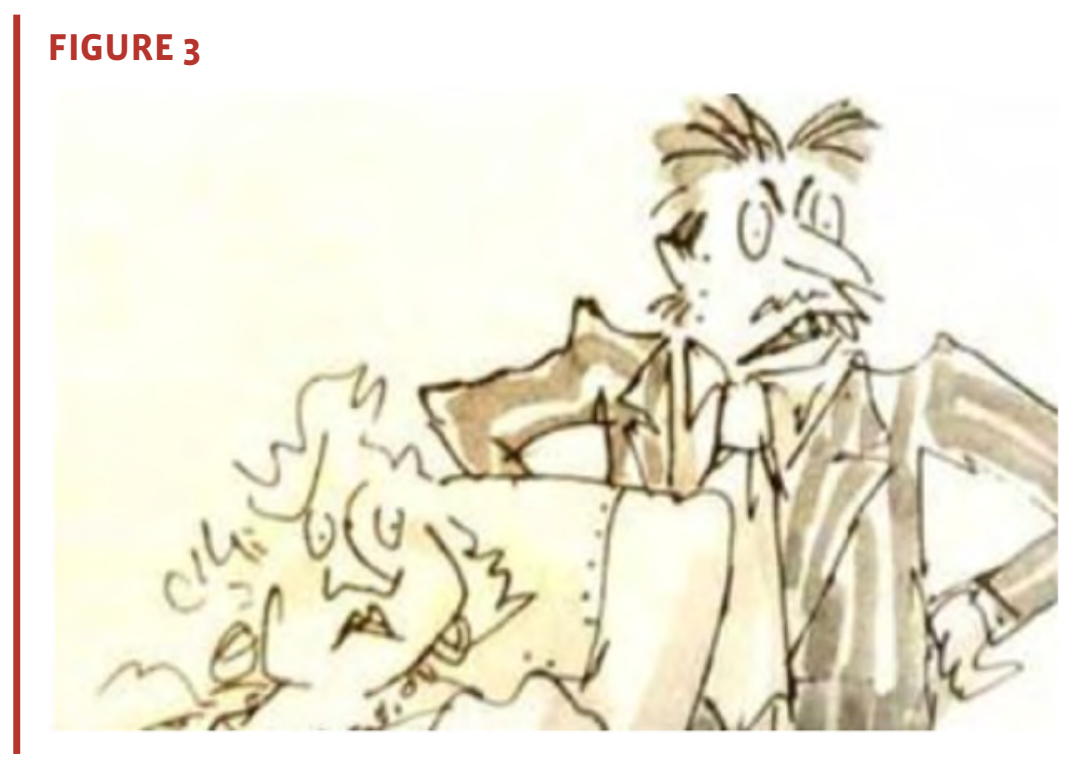

The most salient case that departs from this negative pattern in adults' depiction is that of Miss Honey. Described as a warm person with a lovely face, Blake establishes a symmetrical dynamic between picture and text by providing a literal translation when drawing the character. A case in point can be found on page 62, where Blake mirrors the description provided by the writer: "she had a lovely pale oval madonna face with blue eyes and her hair was light brown. Her body was so slim and fragile..." (p. 60). All these elements are present in Blake's en- 
graving. But beyond the description of the young professor, another point worth commenting on is the similarities between Miss Honey and the librarian.

Despite the absence of a specific description of the latter, she shares several similarities with Miss Honey: she has light hair, she wears the same type of glasses, and she has the same loving look in her eyes and grimace of understanding in her face. In short, she looks like an older version of Miss Honey herself. In this respect, there is a process of transcreation based on a parallelism with another figure of the story: Blake is free to shape the librarian's physique, but he seems to take Miss Honey as his model. With respect to this character, Blake's engravings allow the reader to fill in the numerous blanks the writer left when characterizing this woman. The extent to which the non-narrative element expands on the meaning of the text makes this a case of "extreme enhancement" that, following Nikolajeva and Scott's (2001) tenets, should be categorized as a case of complementary dynamic between the narrative element and its corresponding illustration.

As commented at the beginning of this section, Matilda's physical description is rather interesting as well, especially since there is not a specific one. Readers get some hints throughout the novel ("this tiny dark-haired person sitting there with her feet nowhere near touching the floor" on page 10), but in this regard, the illustrator is almost free to do whatever he sees fit within the implicit limits established by the child's personality, thus building a process of transcreation from text into picture. Matilda is eventually depicted, in Blake's own words (2013), as a little (very little) girl with rounded cheeks and forehead as two features traditionally associated with older people. In Dahl's opinion, the portrait crafted by Blake helped underline Matilda's fragility and tininess (Blake, 2013).

All the decisions taken when depicting Matilda, Miss Honey, and the librarian reinforce the positive light shed on literature and education by the author, since both elements are somehow linked to the most intelligent and benevolent characters of the story and the only ones that transmit a set of positive values to the reader. In other words, books and education are central to all those characters that kids may take as role models, and this is something the dynamics between text and pictures underline both subtly and superficially. In the same vein, the negative portrait of the other adults in the story serves a similar purpose. In this instance, symmetrical and enhancing dynamics underline the concepts of tyranny, idiocy, and abuse Dahl has always attributed to (a part of) his elder characters.

Adults' abuse of power is not only one of the main topics underneath the plot, but also the trigger for some of the funniest passages of the novel: the pranks children play on their elders. These events are, in turn, linked to another recurrent topic in Matilda and other popular books by the same author: rebellion commonly embodied in kids and their behavior. As West (1992) pointed out in his extensive study on the author, Matilda is an example of struggle against tyranny in which kids' uprising is probably the most salient epitome of this crusade. 
This specific issue has polarized the viewpoints of literary critics regarding Dahl's children literature, and Matilda's case is not an exception. On the one hand, we can find opinions like Hunt's (2001), who claimed that Dahl's heroes and heroines-including Matilda-are driven by sheer hate, prejudice and violence, being these elements the triggers of their revenge. On the other, authors like West (1992) defended that Matilda is one of Dahl's greatest heroes, not only due to her outstanding qualities and intellect, but also to her constant fight against adult's tyranny. This issue also allows middle-ground viewpoints to arise like Guest's (2008), who basically portrays Matilda as a rebel against adult's oppression but an adherent of the patriarchal scheme ruling society. Nevertheless, despite all the disagreement it may cause the way Dahl approaches this topic, it is a fact that kids' uprising against the power of adults is a core issue in Matilda.

Several passages of the text and their corresponding pictures may help us illustrate the previous statement. It is worth stressing that the pranks kids play on their "enemies" encompass several pages (even several chapters in some cases): Dahl takes his time to explain how the prank incepts, develops, and concludes. Likewise, Blake decides to depict each prank via a series of illustrations, thus mirroring Dahl's sequence of events. In other words, acts of rebellion are extensively described, both via narrative and non-narrative elements. The first case following this pattern occurs in chapter 3, "The Hat and the Superglue."

In this episode, Dahl describes how Matilda steals one of her father's hats and applies some superglue on it. Thus, after putting his hat on, the father is incapable of taking it out; eventually, Miss Wormwood has to cut the hat out of her husband's head, giving him an extremely ridiculous aspect. Throughout the pages that encompass the prank, Blake concentrates on the main events of Matilda's trick. Therefore, he illustrates how the little girl slips "into the cloakroom" and gets "hold of the hat (her father) wore every day" (p. 24). Subsequently, he shows us how Miss Wormwood gives "the hat a sharp yank" while her husband lets "out a yell that rattled the window-panes" (p. 26). Blake also depicts the ridiculous moment when Mr. Wormwood is going to bed with his hat on, the point in which his wife "took a pair of scissors and cut the thing off his head, bit by bit, first the top and then the brim" (p. 30), and, finally, the resulting looks of Matilda's father. All these narrative elements are included in Blake's engravings (see figure 4), thus providing a literal translation that renders the action directly into pictures.

Other examples throughout the novel follow the same pattern. Another similar case starts in the chapter titled "Lavender", in which we can see how Lavender seeks to avenge all the previous offences committed by Miss Trunchbull against her peers by imitating her admired Matilda. The girl starts her revenge grabbing a newt from a pond. Blake depicts the whole process by including a series of pictures on the same page (p. 132): Lavender "laying on the bank (...) waiting patiently" (p. 131), then "using her school hat as a net" (p. 131), grabbing the newt, and eventually getting it into her pencil box. All these narrative elements are literally translated by Blake and included in the sequence of pictures. 


\section{FIGURE 4}
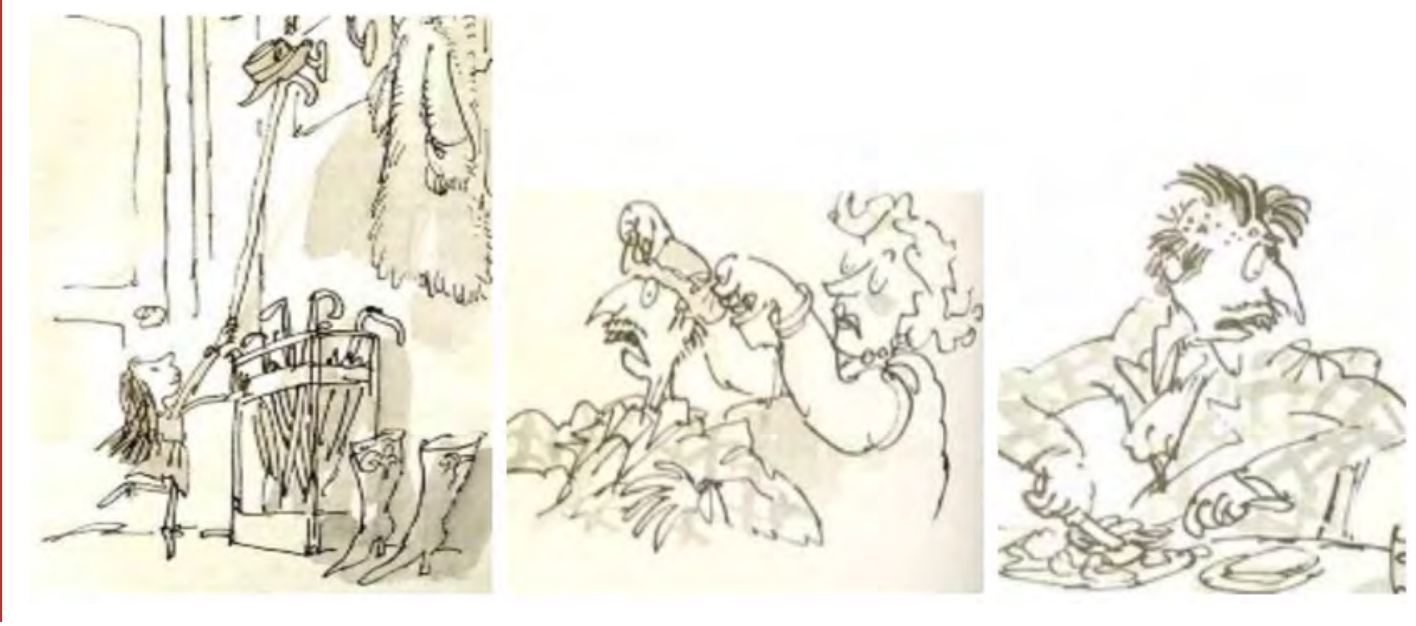

The outcome unravels two chapters later ("The first miracle"), and it is divided into two parts. First, Trunchbull discovers the newt, "let out a yell and leapt off her chair" (p. 155) before she starts "quivering like a blancmange" (p. 155). After blaming Matilda and arguing with her, the protagonist tries - and achieves - to upset the glass of water with the newt. When it happens, "the water in it and the squirming newt splashed out all over Miss Trunchbull's enormous bosom" (p. 160), and the school's principal is astonished for the second time. The prank has succeeded and, one more time, Blake has depicted the whole sequence of events, focusing on small details like the first slight moves of the glass, thus foregrounding the relevance of kids' endeavors to rebel against adults' authority.

In both cases, Blake could have chosen to portray other events occurring in the narration: Matilda's father at work with his hat on, Lavender entering the deserted classroom, or other relevant scenes. However, he provides a sequence in which we can see the underpinning moments of the process by which the kids prepare and carry out their tricks against adults (inception, most embarrassing moments, final outcome). And eventually, the illustrator shows us the kids' success. As mentioned above, these are not the only occasions in which Blake follows this pattern. By replicating this structure in several points of the novel, Blake provides a faithful description of what Dahl narrates in the novel; at the same time, the illustrator forces the reader to focus on the acts of rebellion conducted by kids, foregrounding their counterattacks against adults' repression. All these decisions are channeled through the creation of symmetric dynamics between text and picture, and they help underline the importance of kids' rebellion in Matilda. In parallel, they highlight the triumphs of children over adults, reinforcing the overall negative depiction of adulthood presented by Dahl (with the aforementioned exception of Miss Honey).

Some of the most salient acts of rebellion are a response to the last topic I intend to deal with in this paper: school mistreatment. In Matilda's case, this theme is obviously channeled 
via the figure of Miss Trunchbull. Uprisings against her figure are the kids' way to oppose the dictatorship she has imposed in the school (Culley, 1991). And this dictatorship is revealed in the principal's behavior and personality throughout the novel: strict, obsessed with control and rules, and merciless when one of the students dares to break her norms.

Blake depicts these features using a similar structure to the one followed when portraying kids' pranks: he draws a series of events which normally encompasses the inception, performance, and outcome of the principal's retribution. The depiction of these sequences tends to follow a literal translation process, since Blake reflects the scenes described by Dahl with minor modifications (such as the addition of books and pencils thrown into the air by the kids on page 125 , an element that reinforces the feeling of joy they transmit) or no changes at all. However, this pattern, albeit present throughout the second part of the novel, does not unfold in the same manner in every case: although complete in some occasions, Blake's series of engravings leave some blanks for the reader to fill in in certain instances. These dissimilarities establish different dynamics between the pictures and the passage they represent.

In Roald Dahl's Matilda (2016 [1988]), illustrating a sequence of events tends to meet the purpose of visually describing a given process divided into several steps. Thus, if the series provides a thorough explanation, the dynamic text-illustration would be different to that of a sequence that skips a specific stage or stages. This distinction can be clearly exemplified by contrasting Miss Trunchbull's punishments. On the one hand, some of them include a thorough pattern that begins with a reprimand, continues with the escalade of the punishment, and concludes by showing its final consequences. A case in point are the events occurring in the chapter "Throwing the Hammer". In this instance (see figure 5), Blake provides a literal translation based on passages like those that describe the school's principal "swinging (Amanda) round and round her head, faster and faster" or "pivoting expertly on her toes, spinning round and round" (p. 108); the consequence of Miss Trunchbull revisiting her days of Olympic glory is also presented via a process of literal translation, with Amanda "sat up" looking "a trifle dazed" (p. 110). In this case, the choices made by Blake create a symmetrical relationship where the illustration replicates the events conveyed by the narrative text.

On the other, we find the example of the chapter "Bruce Bogtrotter and the Cake". Here, there is no illustration depicting the very final stage of Miss Trunchbull's punishment. There is not a picture where she raises the china platter "in the air and brought it down with a crash right on the top" of the student's head (p. 127). Likewise, we cannot see Bogtrotter with an indelible smile on his face after the hit (p. 127). If we compare this series of illustrations to the one described in the previous paragraph, we find out that Blake's decision establishes a complementary dynamic. In this example, illustrations initiate a course of action they do not conclude. Thus, readers should bring the sequence to an end by reading the text and mentally depicting how Miss Trunchbull breaks the plate on Bogtrotter's head. This fill-in-the-gap relationship takes enhancement to a next level, thus creating a dynamic of complementarity. 


\section{FIGURE 5}

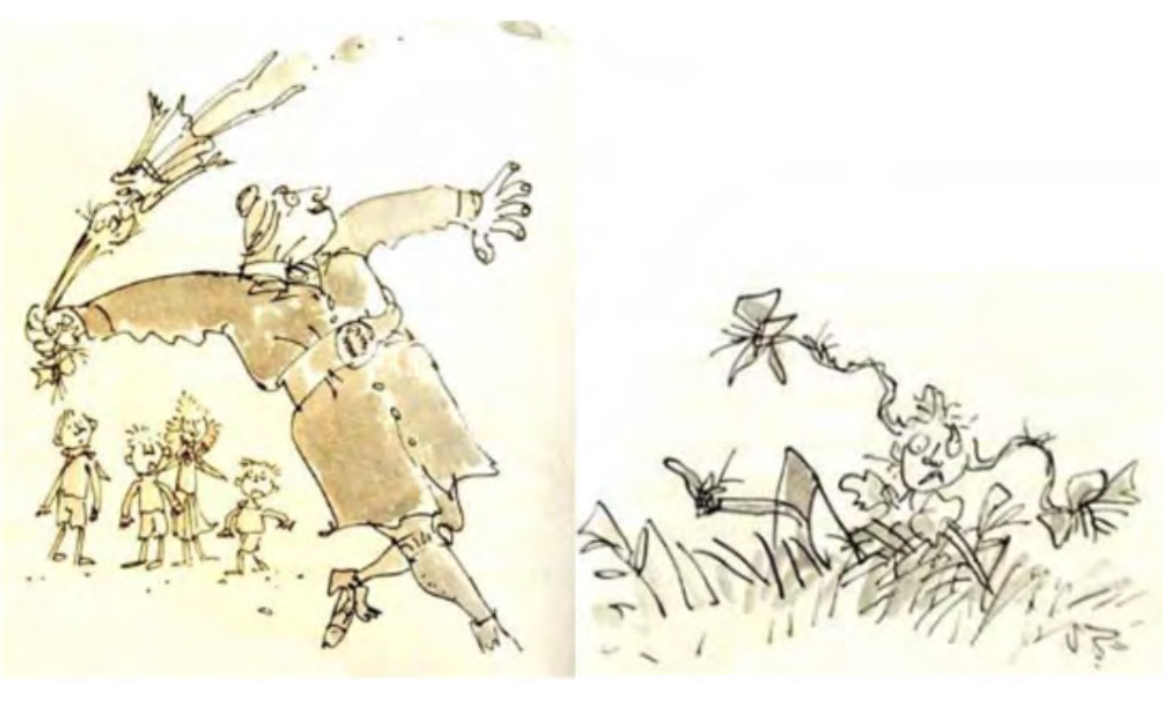

All the examples presented throughout this section categorize text-illustration dynamics as symmetrical, enhancing, or complementary. This implies that illustrations either reflect the same as the original text or add further details that expand on the information offered by words. In addition to its effectiveness as emphasizer of the main topics, the strategy followed by Blake is, in my view, the most appropriate given the audience the book is aimed at. Since children are the most likely addressees of this novel, a too-demanding dynamic like the one created in cases of contradiction or counterpoint may puzzle the readership and create a misunderstanding that could be difficult to unravel by so young readers. Therefore, limiting dynamics to the three cases used by Blake boosts comprehension and allows readers an easier identification of characters' most distinctive features by aligning the information received by words and pictures.

\section{Conclusion}

As stated in the introduction, this paper has taken an innovative approach to Roald Dahl's (2016 [1988]) novel Matilda. Using the concept of transmutation as its main basis, this study has addressed the dynamics established between text and illustrations throughout the book. However, categorizing such dynamics was not its only purpose.

The analysis conducted and presented on these pages has proven how several illustrations in Roald Dahl's Matilda (2016 [1988]) work as emphasizers of some of the main topics addressed by the Welsh writer in this novel. The illustrator's decisions in the examples analyzed do not betray the original work but, in some passages, they establish an asymmetrical relationship between text and pictures aimed at enhancing some of the core themes on which the novel is based. 
In this vein, Blake follows two main strategies: sometimes he just underlines the obvious by replicating what Dahl expressed with his words; in other occasions, he adds new elements or takes specific structure decisions to draw the reader's attention to items and events that tally with some paramount topics approached by Dahl in this work. Thus, the importance of books and education, adults' use of power, kids' rebellion against their elders' behavior, or school mistreatment are not only explicit or implicitly present in the text, but also visible thanks to Blake's illustrations.

The decisions taken by Blake match the concepts of literal translation, transcreation, and amplification. Besides, his pictures also include the repetition of certain drawing patterns when similar situations, such as the pranks played by kids on adults, are repeated throughout the book. These choices establish different interrelations between passages and engravings. In some cases, they are symmetrical; in some others, these dynamics become enhancing or even complementary. But beyond the results we may obtain after an individual analysis, when all the aforementioned examples are scrutinized as a whole, we can ferret out that they fulfill another purpose: emphasizing the most relevant topics addressed by the original author and making them visible so the tandem pictures-text eventually transmits the messages and morals intended by Dahl.

All things considered, I believe the initial hypothesis of this paper has been sufficiently proven. In my view, the emphasizing result of Blake's illustrations is a wise decision that foregrounds key points of the narration so that readers do not miss any of the social critiques and morals included by Dahl. The constant presence of books, the way adults are depicted, or the great detail with which rebellious acts are portrayed help to draw the readers' attention to the issues that really matter, creating a notable symbiosis with the text that will probably help younger readers (maybe after perusing the novel for a second time) to understand that Matilda is not light reading, but an example of profound literature.

\section{References}

ALsINA, Victòria, 2012: "The translation of idiolect in children's literature: The Witches and Matilda by Roald Dahl” in Martin B. Fischer and Maria WIRF NARo (eds.): Translating Fictional Dialogue for Children and Young People, Berlin: Frank \& Timme, 145-164.

BLAKE, Quentin, 2013: Words and Pictures, London: Tate Publishing.

Culley, Jonathon, 1991: "Roald Dahl-'It's about children and it's for children'-but is it suitable?”, Children's Literature in Education 22 (1), 59-73.

CurTis, James M., 2015: "In Absentia Parentis: Confronting the Uncanny Orphan in Roald Dahl's James and the Giant Peach", Children's Literature Association Quarterly 40 (4), 355-370. 
DaHL, Roald, 1984: Boy, London: Penguin Books.

DaHL, Roald, 2016 [1988]: Matilda, London: Puffin Books.

De Juan, Luis, 2016: "Looking into the Patriarchal World of Roald Dahl's Short Story 'Taste' through and Beyond its Narrator", The Grove - Working Papers on English Studies 23, 23-34.

Del Fresno Fernandez, Mercedes, 2009: "Matilda: Realismo y sátira en la obra de Dahl”, Didáctica (Lengua y Literatura) 21, 143-155.

GUEST, Kristen, 2008: "The good, the bad, and the ugly: Resistance and complicity in Matilda", Children's Literature Association Quarterly 33 (3), 246-257.

Hunt, Peter, 2001: Children’s Literature, Oxford: Blackwell.

HURTADO AlBiR, Amparo, 2001: Traducción y traductología, introducción a la traductología, Madrid: Cátedra

Jakobson, Roman, 2000 [1959]: "On Linguistics Aspects of Translation" in Lawrence Venutı (ed.): The Translation Studies Reader, London, New York: Routledge, 113-118.

KenYon, Ghislaine, 2016: Quentin Blake: In the Theatre of the Imagination, London, New York: Bloomsbury.

KeYSER, Catherine, 2017: "Candy Boys and Chocolate Factories: Roald Dahl, Racialization, and Global Industry", Mfs-Modern Fiction Studies 63 (3), 403-428.

Lotman, Yuri M., 2001: Universe of the Mind: A Semiotic Theory of Culture, London, New York: I. B. Tauris Publishers.

Martín Ortiz, Patricia, 2009: "Presencia del humor en la literatura de Roald Dahl”, Anuario de Investigación en Literatura Infantil y Juvenil 7 (2), 87-98.

NetLey, Noriko Shimoda, 1992: "The difficulty of translation: Decoding cultural signs in other languages", Children's Literature in Education 23 (4), 195-202.

Nikolajeva, Maria, and Carole Scott, 2000: "The Dynamics of Picturebook Communication", Children's Literature in Education 31 (4), 225-239.

Nikolajeva, Maria, and Carole Scott, 2001: How Picturebooks Work, London, New York: Garland Publishing.

Petzold, Dieter, 1992: "Wish-fulfilment and subversion: Roald Dahl's Dickensian fantasy Matilda", Children's Literature in Education 23 (4), 185. 
Pope, James, and Julia Round, 2015: "Children's responses to heroism in Roald Dahl's Matilda", Children's Literature in Education 46 (3), 257-277.

Quiles Cerrillo, Julia, 2016: "Procesos de enseñanza-aprendizaje en la literatura de Roald Dahl”, ED ETANIA 49, 147-162.

RAy, Rebecca, and Nataly Kelly, 2010: Reaching New Markets through Transcreation, Massachusetts: Common Sense Advisory, Inc.

Schwarcz, Joseph, 1982: Ways of the illustrator: Visual communication in children's literature, Chicago: American Library Association.

Siegel, Robert, and Audie Cornish, 2013: "Roald DahI Wanted His Magical 'Matilda' To Keep Books Alive" [http://www.npr.org/2013/11/14/245222230/roald-dahl-wanted-his-magical-matilda-tokeep-books-alive, date of retrieval: November 14, 2016].

Torop, Peeter, 2003: "Intersemiosis and intersemiotic translation” in Susan Petrilli (ed.): Translation, Translation, Amsterdam, New York: Rodopi, 271-283.

Vinay, Jean Paul, and Jean Darbelnet, 1995: Comparative Stylistics of French and English: A Methodology for Translation, Amsterdam, Philadelphia: John Benjamins.

West, Mark, 1992: Roald Dahl, New York: Twayne. 